\title{
Surface Corrosion and Microstructure Degradation of Calcium Sulfoaluminate Cement Subjected to Wet-Dry Cycles in Sulfate Solution
}

\author{
Wuman Zhang, Sheng Gong, and Bing Kang \\ School of Transportation Science and Engineering, Beihang University, Beijing, China \\ Correspondence should be addressed to Wuman Zhang; wmzhang@buaa.edu.cn
}

Received 31 May 2017; Accepted 7 September 2017; Published 18 October 2017

Academic Editor: Charles C. Sorrell

Copyright (C) 2017 Wuman Zhang et al. This is an open access article distributed under the Creative Commons Attribution License, which permits unrestricted use, distribution, and reproduction in any medium, provided the original work is properly cited.

\begin{abstract}
The hydration products of calcium sulfoaluminate (CSA) cement are different from those of Portland cement. The degradation of CSA cement subjected to wet-dry cycles in sulfate solution was studied in this paper. The surface corrosion was recorded and the microstructures were examined by scanning electron microscopy (SEM). The results show that $\mathrm{SO}_{4}{ }^{2-}, \mathrm{Na}^{+}, \mathrm{Mg}^{2+}$, and $\mathrm{Cl}^{-}$ have an effect on the stability of ettringite. In the initial period of sulfate attack, salt crystallization is the main factor leading to the degradation of CSA cement specimens. The decomposition and the carbonation of ettringite will cause long-term degradation of CSA cement specimens under wet-dry cycles in sulfate solution. The surface spalling and microstructure degradation increase significantly with the increase of wet-dry cycles, sulfate concentration, and water to cement ratio. Magnesium sulfate and sodium chloride reduce the degradation when the concentration of sulfate ions is a constant value.
\end{abstract}

\section{Introduction}

Calcium sulfoaluminate (CSA) cement was initially developed and produced in China in the late 1960s and was initially designed as an addition to Portland cement (PC) due to its expansive (or shrinkage-compensating) characteristics. Although it has only been in use for less than 50 years, it is one of the most commonly used cements in China and is beginning to be used in all areas of the world [1-3].

Zhu et al. [4] used CSA cement and Silica Fume to design ultrahigh early strength self-compacting mortar. Fu et al. [2], Sahu et al. [5], and $\mathrm{He}$ et al. [6] studied the hydration mechanism of CSA cement. Some researchers have also tried to examine the durability of CSA cement concrete. Zhang et al. [7] investigated influences of water/cement ratio and admixtures on carbonation resistance of CSA cementbased high performance concrete. Geng et al. [8] found that carbonation depth of CSA cement concrete was smaller than that of PC concrete regardless of curing time. Zhao et al. [3] concluded that CSA cement was an ideal cementitious material which can significantly improve the resistance to chloride ion erosion of the concrete. Duan et al. [9] indicated that chloride ions migration coefficient of CSA cement concrete was distinctly smaller than that of Portland cement concrete, especially at early stage. Zhao et al. [10] reported that CSA cement concrete had better chloride ion penetration resistance capacity than Portland cement concrete before and after the freeze-thaw cycle.

Compared with Portland cement, the hydration products of calcium sulfoaluminate (CSA) cement contain rich ettringite, $\mathrm{C}-\mathrm{S}-\mathrm{H}$, and $\mathrm{Al}$ gel, but without $\mathrm{Ca}(\mathrm{OH})_{2}$ phase [11] which is regarded as the source of chemical sulfate attack on concrete. Due to the absence of $\mathrm{Ca}(\mathrm{OH})_{2}$, CSA cement concrete showed excellent resistance against chemical sulfate attack. In addition, field experiences [12] indicate that the concrete surface scaling above sulfate environment ground level is more commonly observed than fully submerged concrete damage. Therefore, the damage of CSA cement concrete partially immersed in sulfate solution is worth being studied for not only the application of CSA cement in sulfate environment but also the further understanding of the socalled physical sulfate attack on concrete [13]. 
TABLE 1: Chemical compositions of cement (\%).

\begin{tabular}{lcccccccc}
\hline & $\mathrm{CaO}$ & $\mathrm{SiO}_{2}$ & $\mathrm{Al}_{2} \mathrm{O}_{3}$ & $\mathrm{Fe}_{2} \mathrm{O}_{3}$ & $\mathrm{MgO}$ & $\mathrm{SO}_{3}$ & $\mathrm{R}_{2} \mathrm{O}^{*}$ & Loss $^{*}$ \\
\hline OPC & 62.28 & 21.08 & 5.47 & 3.96 & 1.73 & 2.63 & 0.80 & 1.61 \\
$\mathrm{CSA}$ & 44.17 & 11.79 & 28.74 & 1.98 & 2.61 & 8.71 & - & 0.16 \\
\hline
\end{tabular}

${ }^{*} \mathrm{R}_{2} \mathrm{O}=\mathrm{Na}_{2} \mathrm{O}+0.658 \mathrm{~K}_{2} \mathrm{O}$.

TABLE 2: Molar concentrations of ions in sulfate solutions.

\begin{tabular}{lccr}
\hline Molar concentration $\left(10^{-4} \mathrm{~mol} / \mathrm{ml}\right)$ & $\mathrm{SO}_{4}{ }^{2-}$ & $\mathrm{Na}^{+}$ & $\mathrm{Mg}^{2+}$ \\
\hline $3 \% \mathrm{Na}_{2} \mathrm{SO}_{4}$ & 2.18 & 4.36 & - \\
$5 \% \mathrm{Na}_{2} \mathrm{SO}_{4}$ & 3.71 & 7.42 & - \\
$3 \% \mathrm{Na}_{2} \mathrm{SO}_{4}+1.80 \% \mathrm{MgSO}_{4}$ & 3.71 & 4.36 & - \\
$3 \% \mathrm{Na}_{2} \mathrm{SO}_{4}+1.80 \% \mathrm{MgSO}_{4}+3 \% \mathrm{NaCl}$ & 3.71 & 9.65 & - \\
\hline
\end{tabular}

\section{Experimental Program}

2.1. Materials. CSA cement, which is industrially produced in Tangshan Six-Nine Cement Industry Co. Ltd. and set by Chinese national standards GB20472-2006, was used. The chemical compositions of CSA cement and ordinary Portland cement (OPC) are listed in Table 1. Four sulfate solutions, namely, $3 \% \mathrm{Na}_{2} \mathrm{SO}_{4}, 5 \% \mathrm{Na}_{2} \mathrm{SO}_{4}, 3 \% \mathrm{Na}_{2} \mathrm{SO}_{4}+1.80 \% \mathrm{MgSO}_{4}$, $3 \% \mathrm{Na}_{2} \mathrm{SO}_{4}+1.80 \% \mathrm{MgSO}_{4}+3 \% \mathrm{NaCl}$, were used. The molar concentrations of ions in sulfate solutions are shown in Table 2.

2.2. Specimens and Tested Program. CSA cement pastes were prepared with tap water and the water to cement ratios $(w / c)$ were $0.30,0.40$, and 0.50 by mass of cement. Molded specimens size was made with $20 \mathrm{~mm} \times 20 \mathrm{~mm} \times 20 \mathrm{~mm}$. After demoulding ( $24 \mathrm{~h}$ after casting), the specimens were cured at a constant temperature $\left(20 \pm 2^{\circ} \mathrm{C}\right)$ and $90 \%$ relative humidity for 28 days.

The wet-dry cycles were carried out by exposure to an alternate conditions. CSA cement specimens were subjected to semi-immersion (two-third part of specimen in solution) in the sulfate solution at $20 \pm 2^{\circ} \mathrm{C}$ for 12 hours and drying in laboratory air at $20 \pm 2^{\circ} \mathrm{C}$ for 12 hours (as shown in Figure 1), during which no temperature effects are considered. This regime is used to simulate cyclic outdoor environments such as rainy days and unclouded days. The wet-dry regime of specimens is shown in Figure 1. The sulfate solution was replaced by the original solution each week in order to provide a constant ions concentration. Spalling samples were taken out from the sulfate solutions and washed by the anhydrous ethanol and acetone to stop their hydration. The microstructure of the CSA cement samples was examined by scanning electron microscopy (SEM).

\section{Visual Assessment of Cube Degradation}

3.1. Effect of Wet-Dry Cycles. Figure 2 shows the surface change of CSA cement $0.50 \mathrm{w} / \mathrm{c}$ specimen subjected to different wet-dry cycles in $5 \% \mathrm{Na}_{2} \mathrm{SO}_{4}$. It is obvious that the degrees of surface spalling or damage increase rapidly with the increase of wet-dry cycles. Firstly, the sodium sulfate crystals and powder particles are observed on the surface after the specimen is subjected to 18 wet-dry cycles. Then the surface layer is stripped off from the specimen when the wetdry cycle increases from 18 to 31 . And the degrees of spalling increase rapidly with the increase of the wet-dry cycles until the specimen is broken into two parts.

SEM images of SAC $0.50 \mathrm{w} / \mathrm{c}$ specimen subjected to different wet-dry cycles in $5 \% \mathrm{Na}_{2} \mathrm{SO}_{4}$ solution are given in Figure 3. Microcrack is not observed from the SEM image of the specimen subjected to 18 wet-dry cycles, although powder particles are found on the specimen surface. However, microcracks are observed when the wet-dry cycle is raised from 18 to 31, and the number and the connectivity of microcracks obviously increase when the wet-dry cycle is 46. The results indicate that the degrees of microstructures degradation increase with the increasing of wet-dry cycles.

3.2. Effect of $W / C$. Figure 4 shows surface change of CSA cement specimens with different $w / c$ subjected to wet-dry cycles in $5 \% \mathrm{Na}_{2} \mathrm{SO}_{4}$ solution. SAC specimen with $0.50 \mathrm{w} / \mathrm{c}$ is broken into two parts when the wet-dry cycle is 46 . However, the specimen with $0.40 \mathrm{w} / \mathrm{c}$ shows a slight surface spalling at the same wet-dry cycle. Two spallings are observed at the corner of the specimen with $0.30 \mathrm{w} / \mathrm{c}$ until the wet-dry cycle increases from 46 to 119 . It can be seen that the degrees of surface spalling increase rapidly with the increase of $w / c$.

SEM images of CSA cement specimens with different $w / c$ subjected to wet-dry cycles in $5 \% \mathrm{Na}_{2} \mathrm{SO}_{4}$ are given in Figure 5. It is clear that the connected microcracks and a long microcrack are observed from the SEM images of the specimen with 0.50 and $0.40 \mathrm{w} / \mathrm{c}$ under 46 wet-dry cycles, respectively. A large number of microcracks are also observed with the specimen with $0.30 \mathrm{w} / \mathrm{c}$ under 119 wet-dry cycles. The results indicate that CSA cement specimens are damaged when they are subjected to a certain number of wet-dry cycles in $5 \% \mathrm{Na}_{2} \mathrm{SO}_{4}$ solution, although the degrees of degradation decrease with the decrease of $w / c$.

It is well known that $w / c$ is an important factor for mechanical properties and durability of cement paste and concrete. Higher $w / c$ makes the porosity higher and the pore structure coarser, which will reduce the durability of cement paste [15]. CSA cement is no exception to this trend. 


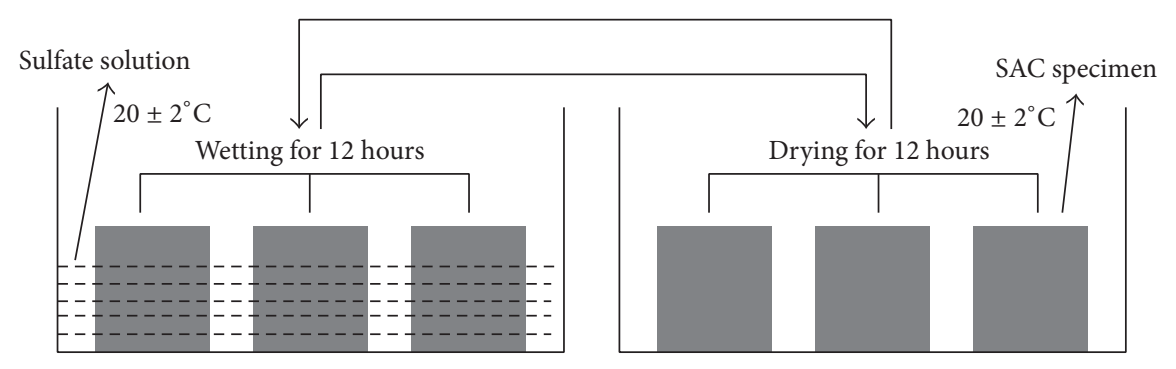

FIgURE 1: The wet-dry regime of specimens.

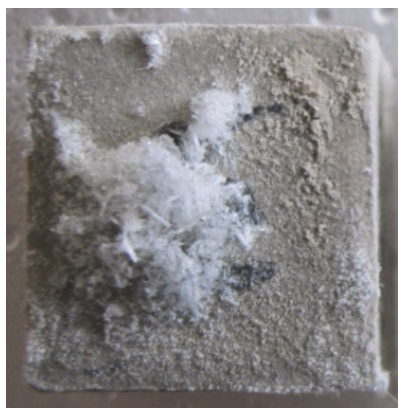

(a) 18 cycles

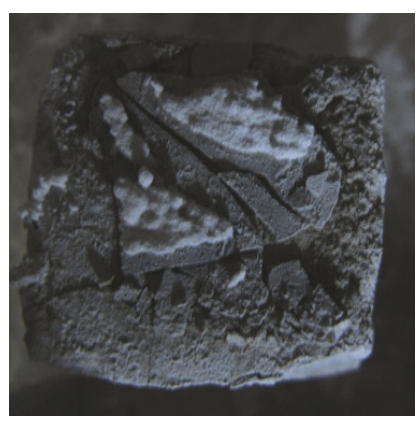

(e) 39 cycles

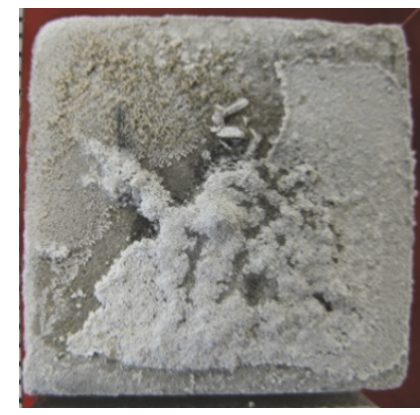

(b) 22 cycles

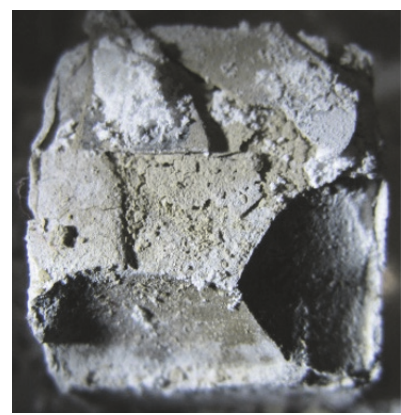

(f) 41 cycles

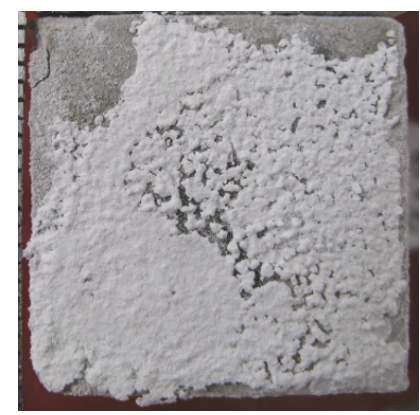

(c) 25 cycles

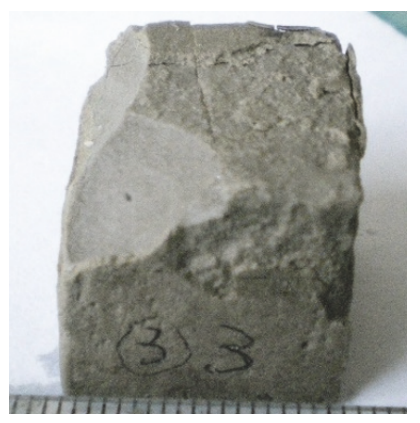

(g) 43 cycles

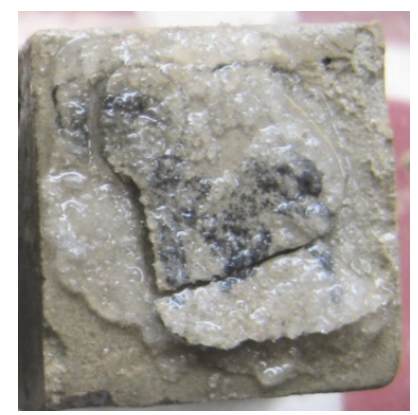

(d) 31 cycles

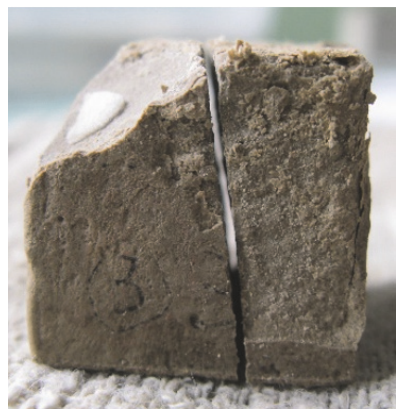

(h) 46 cycles

FIGURE 2: Surface change of CSA cement $0.50 \mathrm{w} / \mathrm{c}$ specimen under wet-dry cycles in $5 \% \mathrm{Na}_{2} \mathrm{SO}_{4}$ solution.

3.3. Effect of Ion Concentration. Figure 6 shows the surface change and SEM image of CSA cement $0.50 \mathrm{w} / \mathrm{c}$ specimen subjected to 46 wet-dry cycles in $3 \% \mathrm{Na}_{2} \mathrm{SO}_{4}$ solution. It can be seen that $\mathrm{Na}_{2} \mathrm{SO}_{4}$ solution migrates to the surface of specimen during the wetting process and begins to precipitate $\mathrm{Na}_{2} \mathrm{SO}_{4}$ crystals during the drying process. Compared to specimen with the same $w / c$ and wet-dry cycles in $5 \% \mathrm{Na}_{2} \mathrm{SO}_{4}$ solution (see Figures $2(\mathrm{~h})$ and $3\left(\mathrm{~h}^{\prime}\right)$ ), a slight surface spalling and a number of microcracks are observed when the specimen is subjected to wet-dry cycles in $3 \% \mathrm{Na}_{2} \mathrm{SO}_{4}$ solution. However, the degrees of damage decrease significantly. The chemical reactions in the pore solution can occur at any sulfate concentration and decrease the possibility of physical attack due to the consumption of sulfates. Moreover, a low concentration solution decreases the possibility of a chemical reaction [12].

In Figure 7, the surface change and SEM image of CSA cement $0.50 \mathrm{w} / \mathrm{c}$ specimen subjected to 46 wet-dry cycles in $3 \% \mathrm{Na}_{2} \mathrm{SO}_{4}+1.80 \% \mathrm{MgSO}_{4}$ solution are presented. It is clear that the surface spalling is very slight and several microcracks are found in the SEM image. The degree of deterioration of SAC specimen under wet-dry cycles in $3 \% \mathrm{Na}_{2} \mathrm{SO}_{4}+1.80 \%$ $\mathrm{MgSO}_{4}$ solution is lesser than that of specimen subjected to wet-dry cycles in $5 \% \mathrm{Na}_{2} \mathrm{SO}_{4}$ solution. In addition, a large number rod-like crystals are observed in the SEM image.

Figure 8 shows the surface change and microstructures of CSA cement $0.50 \mathrm{w} / \mathrm{c}$ specimen subjected to 46 wet-dry cycles in $3 \% \mathrm{Na}_{2} \mathrm{SO}_{4}+1.80 \% \mathrm{MgSO}_{4}+3 \% \mathrm{NaCl}$ solution. There is almost no change except a crack on the edge of the surface. It also can be seen that there is a very few microcracks in the SEM image of specimen. Chloride ions have a higher rate of diffusion than that of the sulfate ions. Chloride ions can permeate through the specimen surface much faster than the sulfate ions and block the internal pore, which decreases the penetration of the sodium sulfate solution. However, this result may be different after a longer wet-dry cycle and this work will be carried out in the future. 


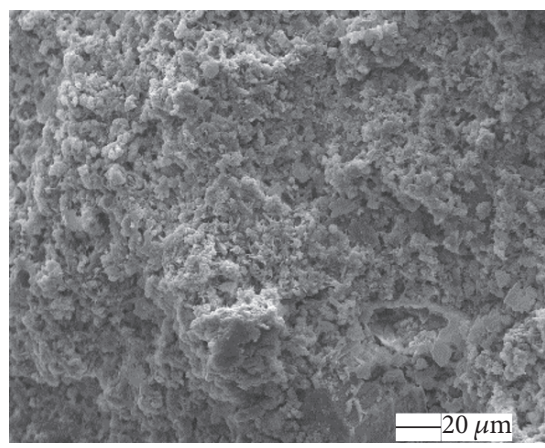

$\left(a^{\prime}\right) 18$ cycles

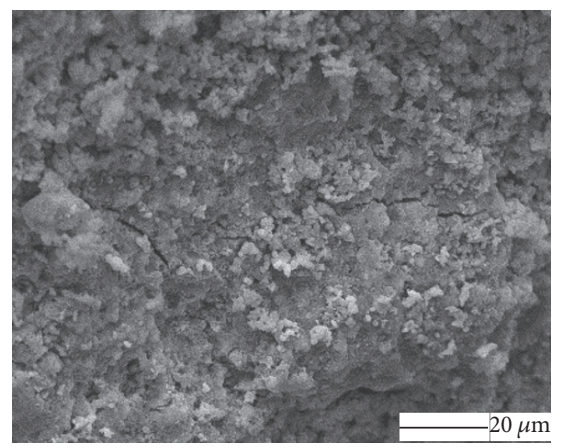

$\left(d^{\prime}\right) 31$ cycles

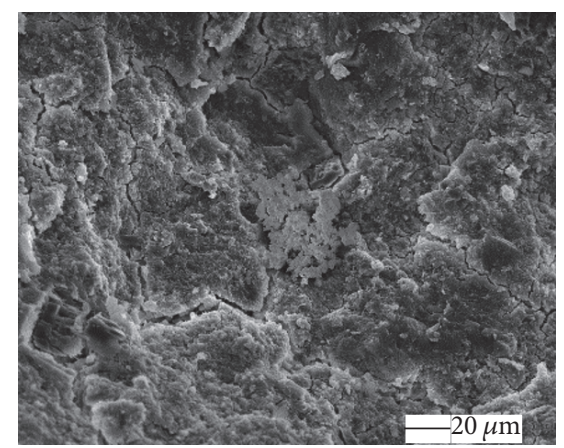

$\left(h^{\prime}\right) 46$ cycles

FIGURE 3: SEM images of CSA cement $0.50 \mathrm{w} / \mathrm{c}$ specimen under wet-dry cycles in $5 \% \mathrm{Na}_{2} \mathrm{SO}_{4}$ solution.

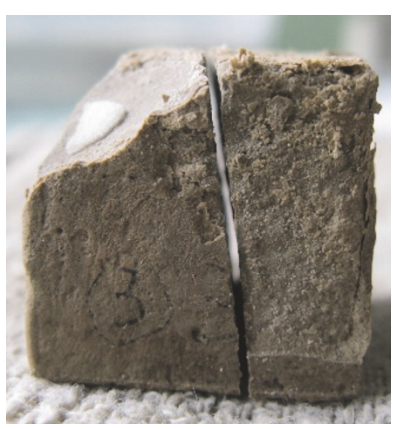

(a) $0.50 \mathrm{w} / \mathrm{c}, 46$ cycles

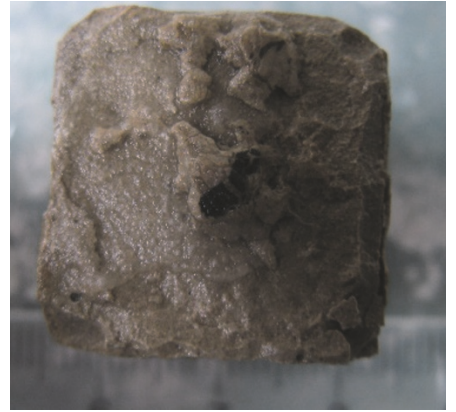

(b) $0.40 \mathrm{w} / \mathrm{c}, 46$ cycles

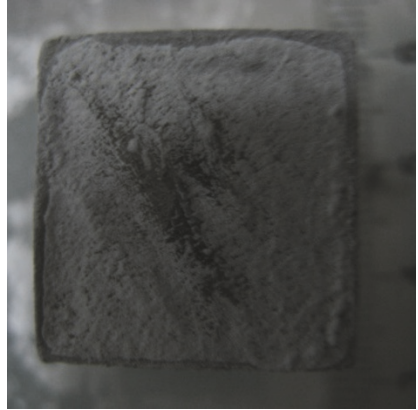

(c) $0.30 \mathrm{w} / \mathrm{c}, 46$ cycles

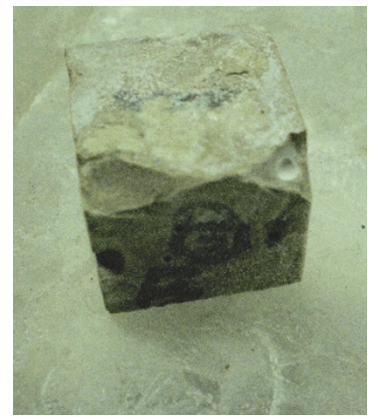

(d) $0.30 \mathrm{w} / \mathrm{c}, 119$ cycles

FIGURE 4: Surface change of CSA cement specimens under wet-dry cycles in $5 \% \mathrm{Na}_{2} \mathrm{SO}_{4}$ solution.

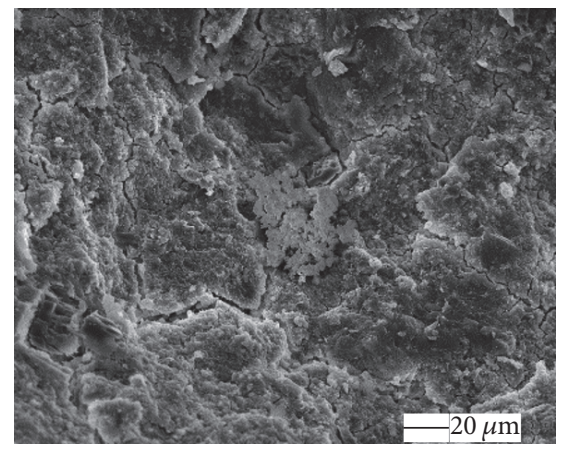

(a') $0.50 \mathrm{w} / \mathrm{c}, 46$ cycles

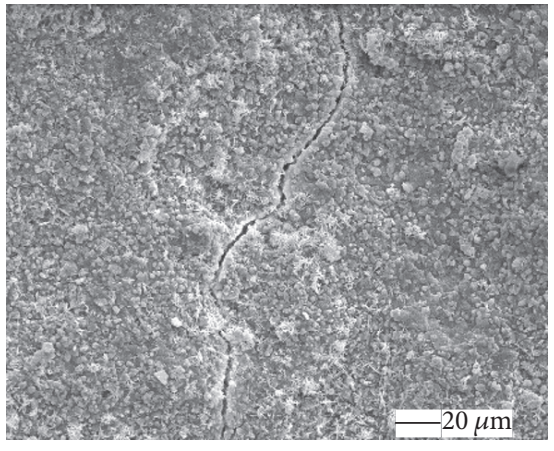

(b') $0.40 w / c, 46$ cycles

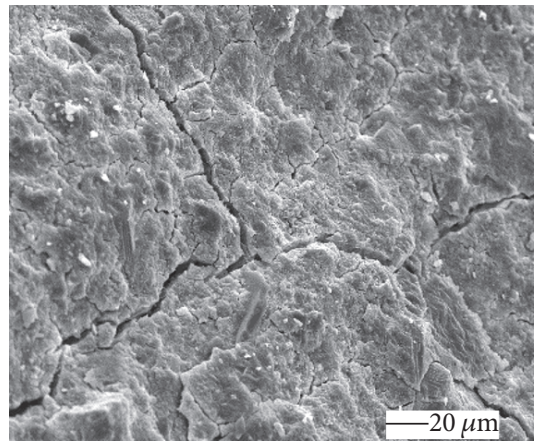

$\left(d^{\prime}\right) 0.30 w / c, 119$ cycles

FIgURE 5: SEM images of CSA cement specimens under wet-dry cycles in $5 \% \mathrm{Na}_{2} \mathrm{SO}_{4}$ solution.

3.4. OPC and CSA Cement. The surface changes of OPC and CSA cement specimens are given in Figures 9 and 10, respectively. It is obvious that there is a significant difference in the surface change between OPC and CSA cement specimens. A serious spalling is observed on each side face and the spalling is mainly above the liquid level in wetting process. There is no significant spalling on the surface of OPC specimen, but netlike cracks are found on each side face. Figure 11 shows the microstructures of OPC and CSA cement specimens. An obvious stripping layer is observed from the SEM image of CSA cement specimens. However, there are no significant microcracks except a certain number of pores in the SEM image of OPC specimen.
This result can be explained as follows. There was a dense process of OPC specimen subjected to sulfate attack because sulfate ions transported into the pore and reacted with calcium hydroxide and calcium aluminate hydrate, to form ettringite and gypsum. The production could block the pore and microcracks in the initial period of sulfate attack [16]. And then the sodium sulfate solution penetrated into OPC specimen would be decreased. However, the chemical reaction may be very slow because of the low $\mathrm{Ca}(\mathrm{OH})_{2}$ content of CSA cement. Much sodium sulfate solution would penetrate into CSA cement specimen during the wetting process, which could rapidly generate a pressure of salt crystallization during the drying process. Therefore, the 


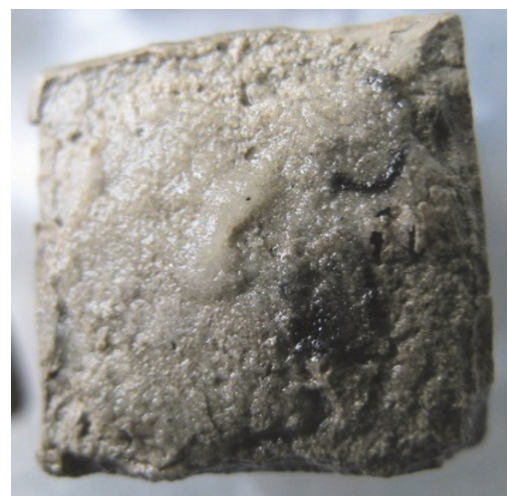

(a) Surface change

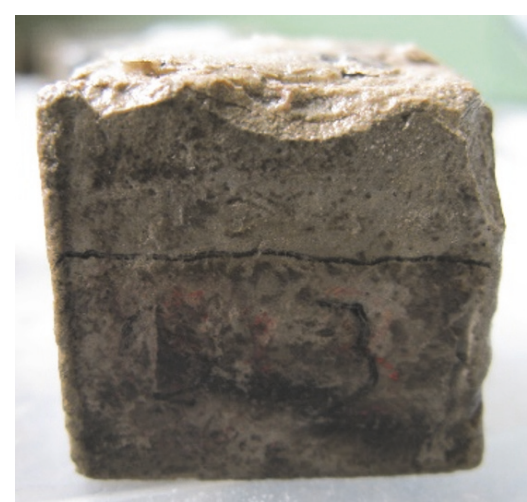

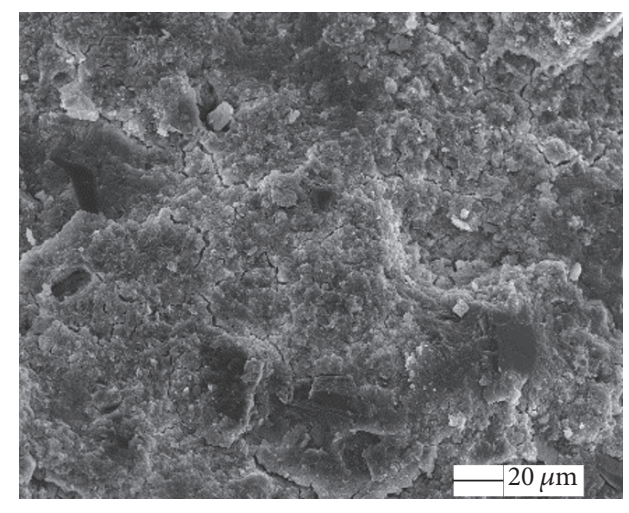

(b) SEM image

FIGURE 6: CSA cement $0.50 \mathrm{w} / \mathrm{c}$ specimen subjected to 46 wet-dry cycles in $3 \% \mathrm{Na}_{2} \mathrm{SO}_{4}$ solution.

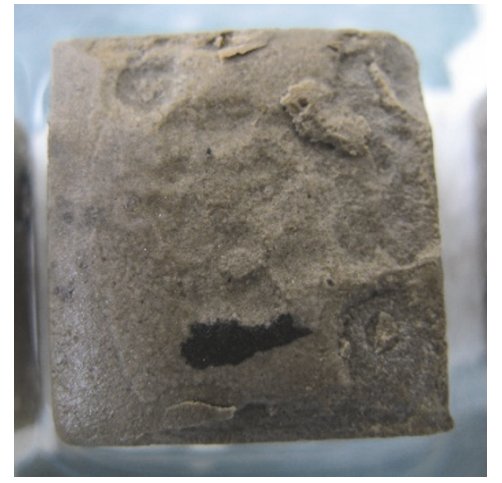

(a) Surface change

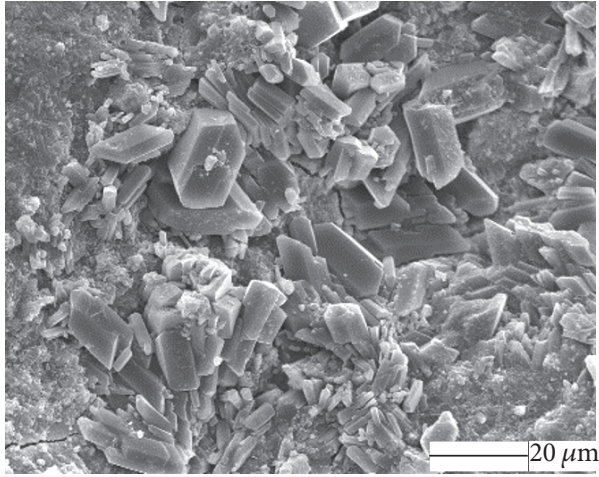

(b) SEM image

FIGURE 7: SAC $0.50 \mathrm{w} / \mathrm{c}$ specimen subjected to 46 wet-dry cycles in $3 \% \mathrm{Na}_{2} \mathrm{SO}_{4}+1.80 \% \mathrm{MgSO}_{4}$ solution.

sulfate attack resistance of CSA cement is not better than that of OPC during the wet-dry cycles.

\section{Discussion of Degradation Mechanisms}

4.1. Degradation Mechanisms in Sodium Sulfate Solution. Sodium sulfate reacts with calcium aluminate hydrate and calcium hydroxide, leading to the formation of ettringite and gypsum, which is the degradation mechanisms of OPC in sodium sulfate solution. However, it is evident that the hydration products of CSA cement are ettringite, C-S-H, and amorphous AH3. Therefore, the above degradation mechanisms are not suitable for CSA cement because there is very little calcium aluminate hydrate and calcium hydroxide in the hydration products of CSA cement [11].

The degradation has been attributed to the physical sulfate attack which can be regarded as a specific type of salt damage. A common form of physical sulfate attack occurs when sodium sulfate crystallizes in the pore structure of cement or concrete. The typical consequence of physical sulfate attack of concrete is surface erosion. In its early stages, it is manifested primarily by the appearance of white crystallites (efflorescence) on a concrete surface (as shown in Figure 2). The composition of the sulfate salt formed is also important; sodium sulfates may interconvert between the 10 hydrate and the anhydrous salt. Thenardite has been reported to be capable of producing pore pressures of 400-5000 psi while mirabilite $\mathrm{Na}_{2} \mathrm{SO}_{4} \cdot 10 \mathrm{H}_{2} \mathrm{O}$ produces pore pressures of 1000-1200 psi [17].

4.2. Degradation Mechanisms in Magnesium Sulfate Solution. Ettringite is the main hydration product of CSA cement. The $\mathrm{Mg}^{2+}$ can influence the stability of ettringite. Figure 12 gives the stability of ettringite as a function of $\mathrm{MgSO}_{4}$ concentration temperature. However the attack reaction can be slow: the kinetics of ettringite decomposition are not rapid even at $85^{\circ} \mathrm{C}$ in normal seawater concentrations, owing in part to the development of semiprotective layers of reaction products on ettringite [14].

In addition, $\mathrm{Mg}^{2+}$ can generate insoluble $\mathrm{Mg}(\mathrm{OH})_{2}$, causing the decomposition of ettringite [18] as the following equation.

$$
\begin{aligned}
3 \mathrm{CaO} & \cdot \mathrm{Al}_{2} \mathrm{O}_{3} \cdot 3 \mathrm{CaSO}_{4} \cdot 32 \mathrm{H}_{2} \mathrm{O}+3 \mathrm{MgSO}_{4} \\
= & 6\left(\mathrm{CaSO}_{4} \cdot 2 \mathrm{H}_{2} \mathrm{O}\right)+\mathrm{Al}_{2} \mathrm{O}_{3} \cdot x \mathrm{H}_{2} \mathrm{O} \\
& +3 \mathrm{Mg}(\mathrm{OH})_{2}+(17-x) \mathrm{H}_{2} \mathrm{O} .
\end{aligned}
$$




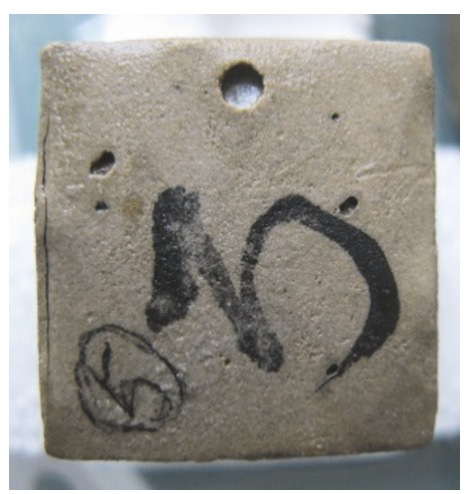

(a) Surface change

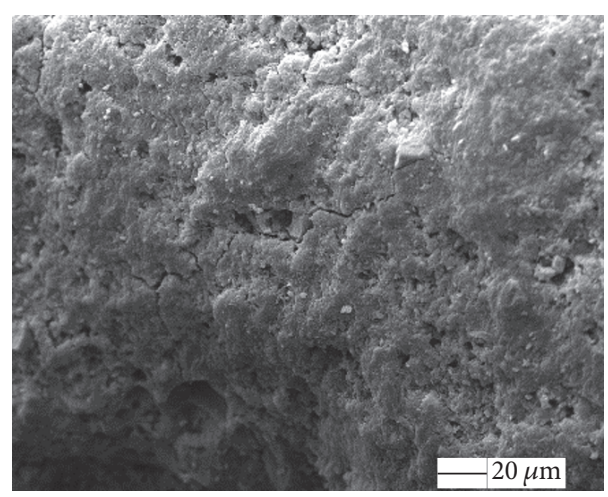

(b) SEM image

Figure 8: CSA cement $0.50 \mathrm{w} / \mathrm{c}$ specimen subjected to 46 wet-dry cycles in $3 \% \mathrm{Na}_{2} \mathrm{SO}_{4}+1.80 \% \mathrm{MgSO}_{4}+3 \% \mathrm{NaCl}$ solution.
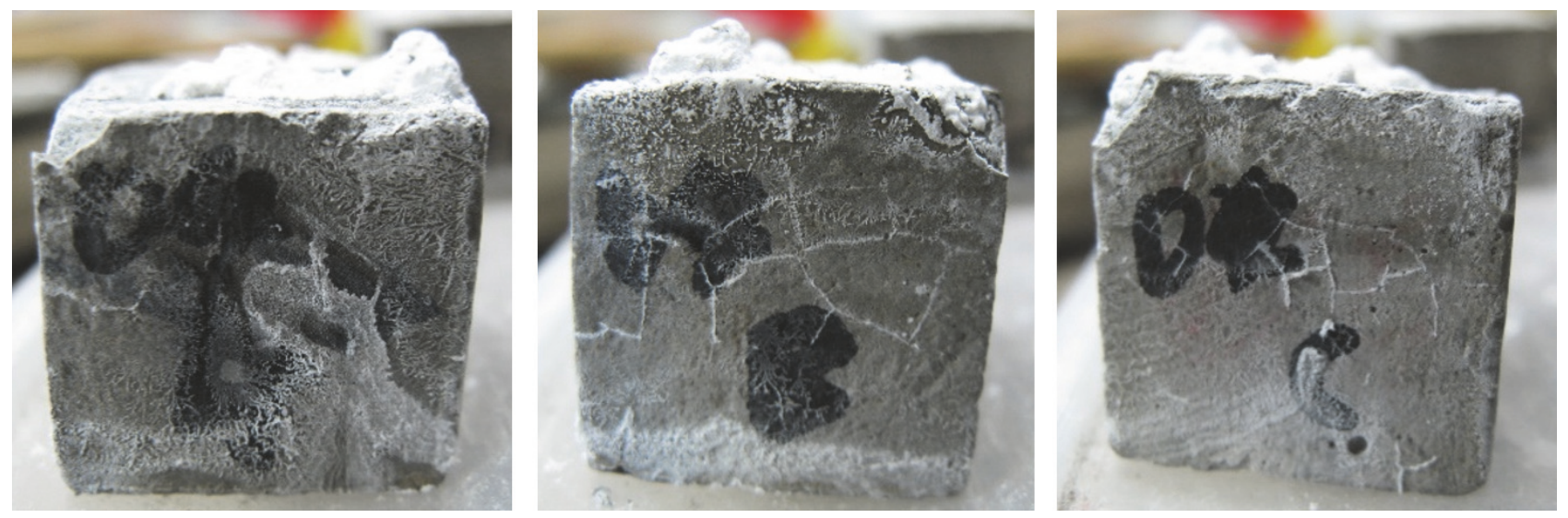

FIgURE 9: OPC $0.40 \mathrm{w} / \mathrm{c}$ specimen subjected to 74 wet-dry cycles in $3 \% \mathrm{Na}_{2} \mathrm{SO}_{4}$ solution.

The damage of the lower part of CSA cement paste in the $\mathrm{MgSO}_{4}$ solution characterized a typical chemical sulfate attack [19]: gypsum starts forming in the region close to the surface due to the solution penetration. The surface zone of the paste, where massive gypsum crystals have been aggregating due to ettringite decomposition, behaves like a skin that is trying to expand. However, the bulk of the paste underneath, which is chemically unaltered, tries to resist this expansion. Thus, a resultant compressive force is generated in the region close to surface causing the outer paste layer detachment. After the outer layer detachment, the same attack process starts causing the second layer formation and detachment and then the third layer and successive layers [13].

\subsection{Degradation Mechanisms in Sodium Chloride Solution.} Both components of $\mathrm{NaCl}$ impact on ettringite stability. Sodium will affect the thermodynamic properties of the aqueous solution coexisting with ettringite and thereby alter its solubility. Chloride has the same action but additionally it stabilises chloride-AFm, Friedel's salt, and this provides another stable host structure which is competitive with ettringite for aluminium. Figure 13 shows experimental data on ettringite stability, based on experiments ranging in duration between 150 and 400 days [14]. It can been seen that at $25^{\circ} \mathrm{C}$ the aqueous sulfate concentration approximately doubles between initially distilled water and $0.5 \mathrm{M} \mathrm{NaCl}$. The combined effect of temperature and sodium chloride content is to enhance markedly sulfate solubilities. Ettringite is partially or wholly converted to one or more AFm phases with sulfate and chloride, the chloride phase being either Friedel's salt or a mixed $\mathrm{Cl}-\mathrm{SO}_{4} \mathrm{AFm}$ phase.

4.4. Degradation Mechanisms by Carbonation. In addition, the stability of ettringite is influenced by carbonation. Ettringite would decompose to $\mathrm{CaSO}_{4} \cdot 2 \mathrm{H}_{2} \mathrm{O}, \mathrm{CaCO}_{3}$, and alumina gel as the following equation [20]:

$$
\begin{aligned}
3 \mathrm{CaO} & \cdot \mathrm{Al}_{2} \mathrm{O}_{3} \cdot 3 \mathrm{CaSO}_{4} \cdot 32 \mathrm{H}_{2} \mathrm{O}+3 \mathrm{CO}_{2} \\
= & 3 \mathrm{CaCO}_{3}+3\left(\mathrm{CaSO}_{4} \cdot 2 \mathrm{H}_{2} \mathrm{O}\right)+\mathrm{Al}_{2} \mathrm{O}_{3} \cdot x \mathrm{H}_{2} \mathrm{O} \\
& +(26-x) \mathrm{H}_{2} \mathrm{O} .
\end{aligned}
$$

The carbonation of ettringite caused the formation of $\mathrm{CaCO}_{3}$ and $\mathrm{CaSO}_{4} \cdot 2 \mathrm{H}_{2} \mathrm{O}$, but the role of carbonation of ettringite in the paste in the solution should be weak. There was another mechanism causing rich $\mathrm{CaSO}_{4} \cdot 2 \mathrm{H}_{2} \mathrm{O}$ formation. According to the basic theory of chemical reaction kinetics the chemical 

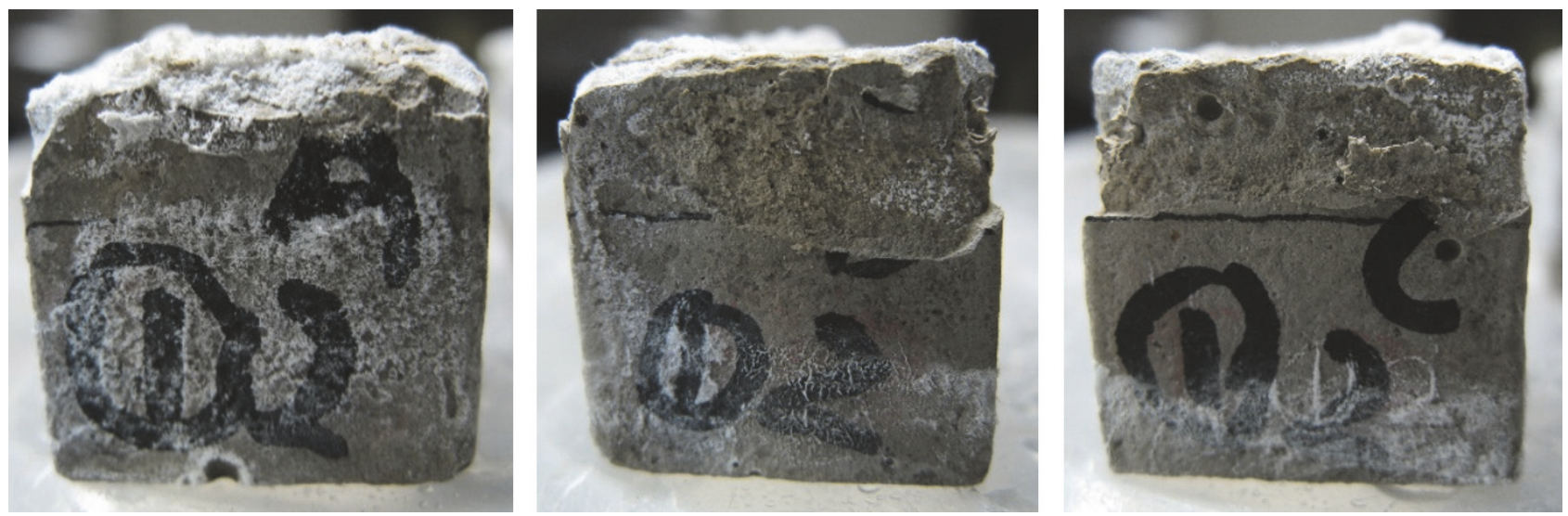

Figure 10: CSA cement $0.40 w / c$ specimen subjected to 73 wet-dry cycles in $3 \% \mathrm{Na}_{2} \mathrm{SO}_{4}$ solution.

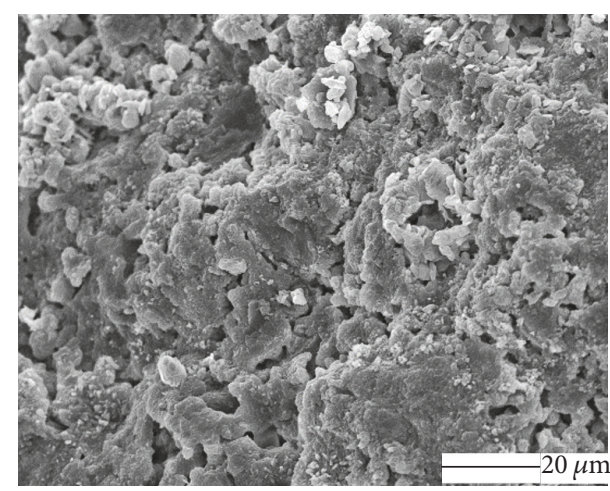

(a) OPC

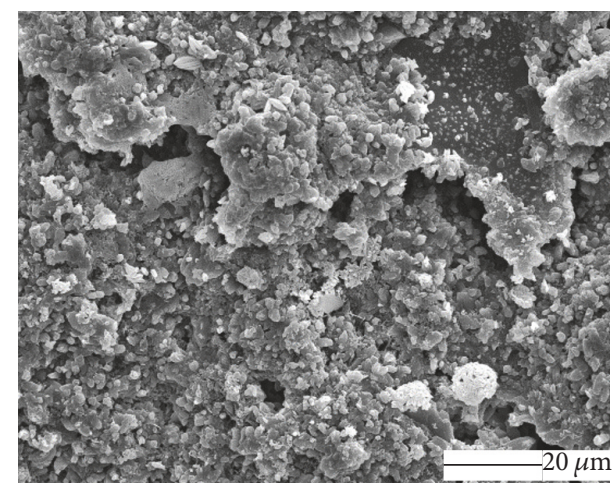

(b) SAC

FIGURE 11: SEM images of OPC and CSA cement specimens.

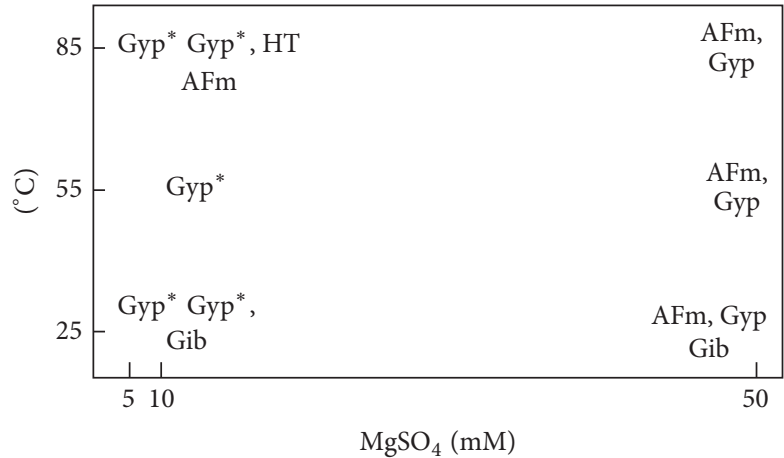

${ }^{*}$ Reaction incomplete ettringite still present Gyp: gypsum, $\mathrm{CaSO}_{4} \cdot 2 \mathrm{H}_{2} \mathrm{O}$ AFm: sulfated monocalcium aluminate hydrate Gib: gibbsite, $\mathrm{Al}(\mathrm{OH})_{2}$ HT: hydrotalcite

FIGURE 12: Stability of ettringite as a function of $\mathrm{MgSO}_{4}$ concentration temperature [14].

reaction has to occur if there is water, gas, or insoluble product formation $[20,21]$.

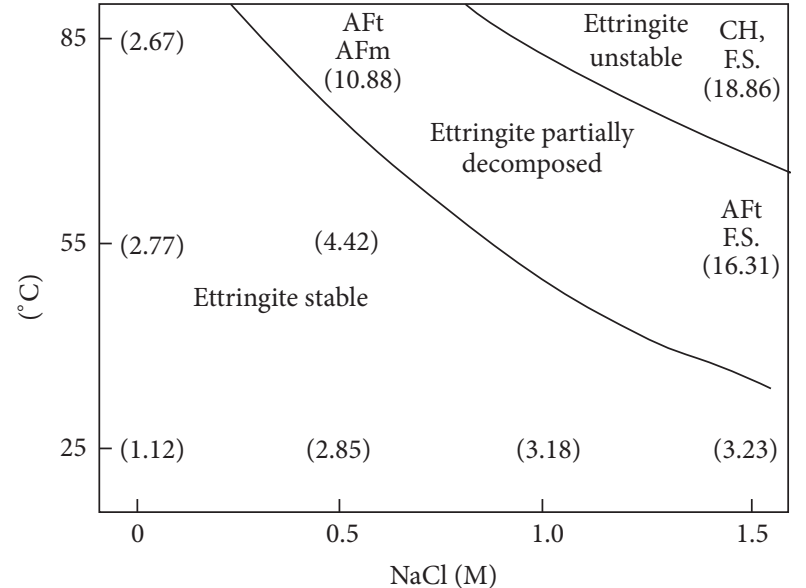

FIGURE 13: Stability of ettringite as a function of $\mathrm{NaCl}$ concentration and temperature [14].

\section{Conclusions}

From the results obtained in this work, the following conclusion can be drawn. 
(1) $\mathrm{SO}_{4}{ }^{2-}, \mathrm{Na}^{+}, \mathrm{Mg}^{2+}$, and $\mathrm{Cl}^{-}$affect the stability of ettringite. In the initial period of sulfate attack, the salt crystallization is the main factor leading to the degradation of CSA cement specimens subjected to wet-dry cycles.

(2) The decomposition and the carbonation of ettringite will cause a long-term degradation of CSA cement specimens under wet-dry cycles.

(3) The surface spalling and microstructure degradation increase significantly with the increase of wet-dry cycles and $w / c$. The degradation increases rapidly when the content of sulfate raises from $3 \%$ to $5 \%$.

(4) Magnesium sulfate and sodium chloride can reduce the degradation when the concentration of sulfate ions is a constant value.

(5) The sulfate attack resistance of CSA cement is not better than that of OPC during the wet-dry cycles.

\section{Additional Points}

Highlights. (1) $\mathrm{SO}_{4}{ }^{2-}, \mathrm{Na}^{+}, \mathrm{Mg}^{2+}$, and $\mathrm{Cl}^{-}$have an effect on the stability of CSA cement. (2) Salt crystallization is the main factor of the degradation of CSA cement subjected to wet-dry cycles in sulfate solution. (3) Visual assessment and microstructure analysis of the degradation of CSA cement occurs.

\section{Conflicts of Interest}

The authors declare that they have no conflicts of interest.

\section{Acknowledgments}

This research was supported by grants from the National Natural Science Foundation of China (no. 51378042, no. 51678022).

\section{References}

[1] G. Edward, Moffatt Durability of Rapid-Set (Ettringite-Based) Concrete, University of New Brunswick, 2016.

[2] X. Fu, C. Yang, Z. Liu, W. Tao, W. Hou, and X. Wu, "Studies on effects of activators on properties and mechanism of hydration of sulphoaluminate cement," Cement and Concrete Research, vol. 33, no. 3, pp. 317-324, 2003.

[3] J. Zhao, G. Cai, and D. Gao, "Analysis of mechanism of resistance to chloride ion erosion of sulphoaluminate cement concrete," Journal of Building Materials, vol. 14, pp. 357-361, 2011.

[4] Y. Zhu, B. Ma, X. Li, and D. Hu, "Ultra high early strength self-compacting mortar based on sulfoaluminate cement and silica fume," Journal Wuhan University of Technology, Materials Science Edition, vol. 28, no. 5, pp. 973-979, 2013.

[5] S. Sahu, J. Havlica, V. Tomková, and J. Majling, "Hydration behaviour of sulphoaluminate belite cement in the presence op various calcium sulphates," Thermochimica Acta, vol. 175, no. 1 , pp. 45-52, 1991.
[6] Z. He, H. Yang, and M. Liu, "Hydration mechanism of sulphoaluminate cement," Journal Wuhan University of Technology, Materials Science Edition, vol. 29, no. 1, pp. 70-74, 2014.

[7] D. Zhang, D. Xu, X. Cheng, and W. Chen, "Carbonation resistance of sulphoaluminate cement-based high performance concrete," Journal Wuhan University of Technology, Materials Science Edition, vol. 24, no. 4, pp. 663-666, 2009.

[8] H. Geng, P. Duan, W. Chen, and Z. Shui, "Carbonation of sulphoaluminate cement with layered double hydroxides," Journal Wuhan University of Technology, Materials Science Edition, vol. 29, no. 1, pp. 97-101, 2014.

[9] P. Duan, W. Chen, J. Ma, and Z. Shui, "Influence of layered double hydroxides on microstructure and carbonation resistance of sulphoaluminate cement concrete," Construction and Building Materials, vol. 48, pp. 601-609, 2013.

[10] J. Zhao, G. Cai, D. Gao, and S. Zhao, "Influences of freeze-thaw cycle and curing time on chloride ion penetration resistance of Sulphoaluminate cement concrete," Construction and Building Materials, vol. 53, pp. 305-311, 2014.

[11] P. Chaunsali, Early-Age Hydration and Volume Change of Calcium Sulfoaluminate Cement-Based Binders, University of Illinois at Urbana-Champaign, 2015.

[12] Z. Liu, D. Deng, and G. De Schutter, "Does concrete suffer sulfate salt weathering?" Construction and Building Materials, vol. 66, pp. 692-701, 2014.

[13] Z. Liu, X. Li, D. Deng, and G. De Schutter, “The damage of calcium sulfoaluminate cement paste partially immersed in MgSO4 solution," Materials and Structures, vol. 49, pp. 719-727, 2016.

[14] F. P. Glasser, The Stability of Ettringite International RILEM Workshop on Internal Sulfate Attack and Delayed Ettringite Formation, K. Scrivener and J. Skalny, Eds., 2004.

[15] R. A. Cook and K. C. Hover, "Mercury porosimetry of hardened cement pastes," Cement and Concrete Research, vol. 29, pp. 933934, 1999.

[16] J. Gao, Z. Yu, L. Song, T. Wang, and S. Wei, "Durability of concrete exposed to sulfate attack under flexural loading and drying-wetting cycles," Construction and Building Materials, vol. 39, pp. 33-38, 2013.

[17] P. W. Brown, "Thaumasite formation and other forms of sulfate attack," Cement and Concrete Composites, vol. 24, no. 3-4, pp. 301-303, 2002.

[18] F. M. Lea, The Chemistry of Cement and Concrete, Edward Arnold, London, UK, 3rd edition, 1970.

[19] M. Santhanam, M. D. Cohen, and J. Olek, "Mechanism of sulfate attack: a fresh look part 2 : proposed mechanisms," Cement and Concrete Research, vol. 33, no. 3, pp. 341-346, 2003.

[20] T. Nishikawa, K. Suzuki, S. Ito, K. Sato, and T. Takebe, "Decomposition of synthesized ettringite by carbonation," Cement and Concrete Research, vol. 22, no. 1, pp. 6-14, 1992.

[21] X. Chen and R. Zou, "Kinetic study of ettringite carbonation reaction," Cement and Concrete Research, vol. 24, no. 7, pp. 13831389, 1994. 

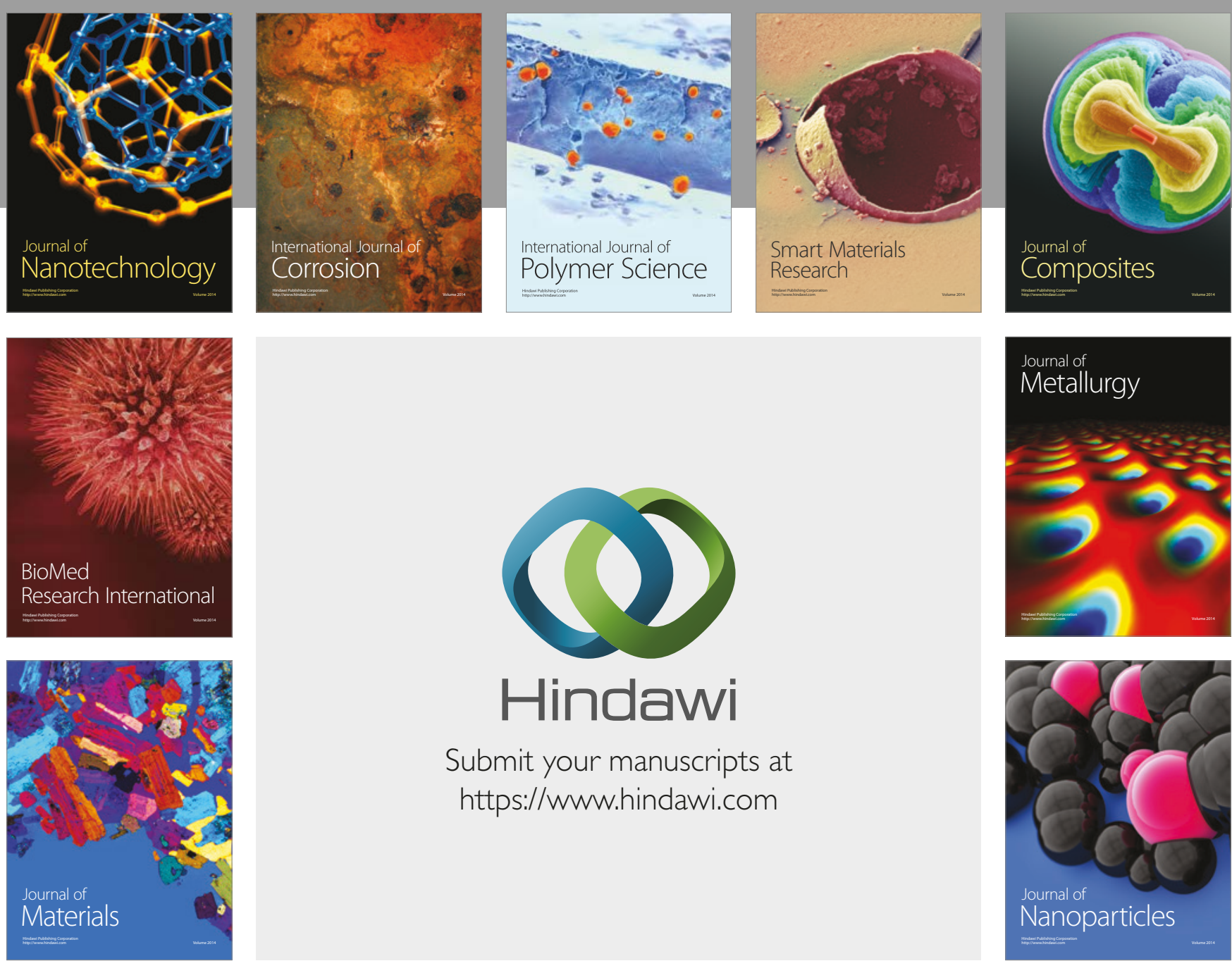

\section{Hindawi}

Submit your manuscripts at

https://www.hindawi.com
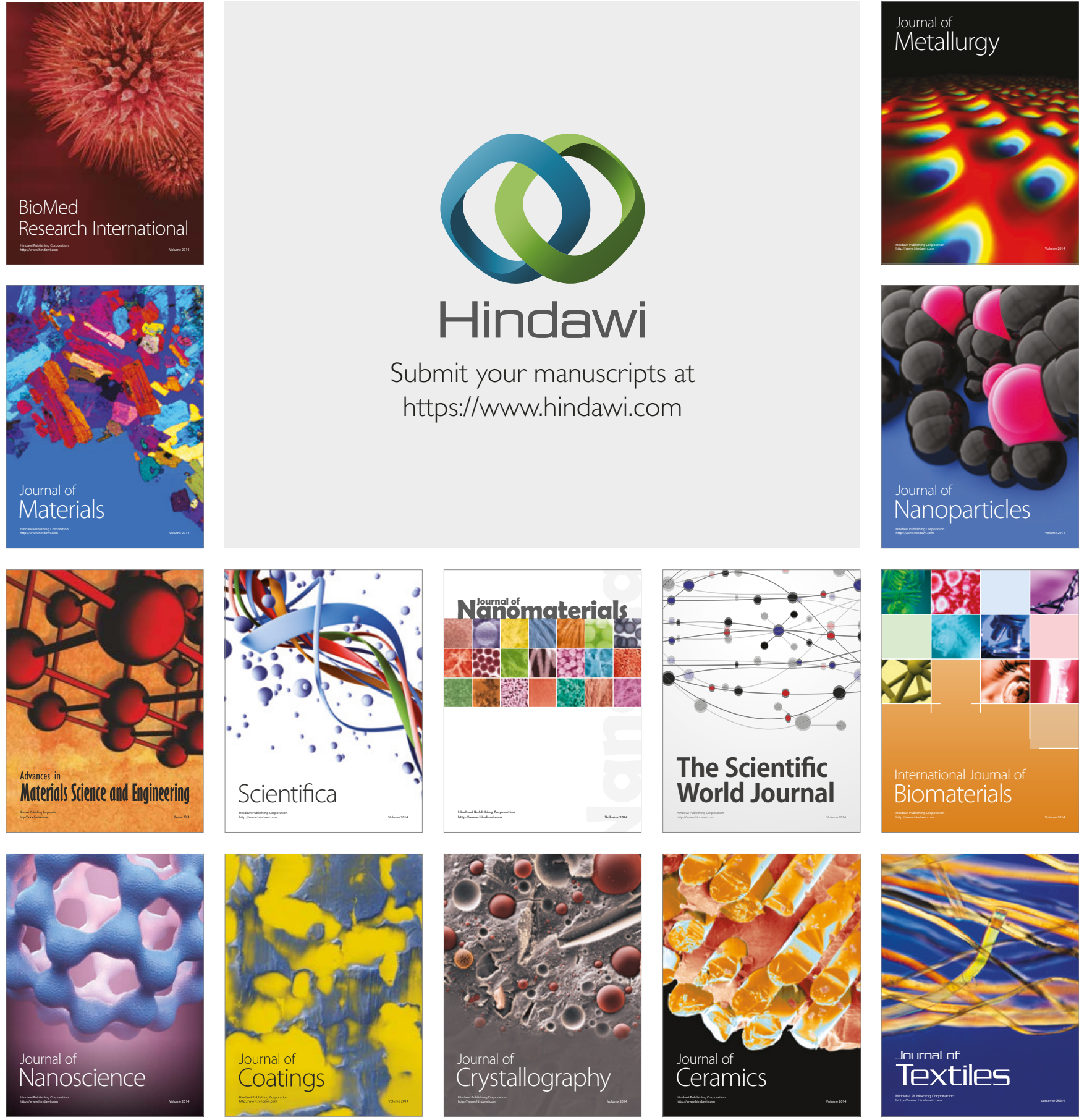

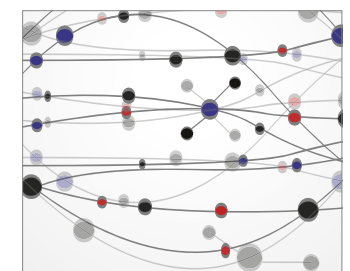

The Scientific World Journal
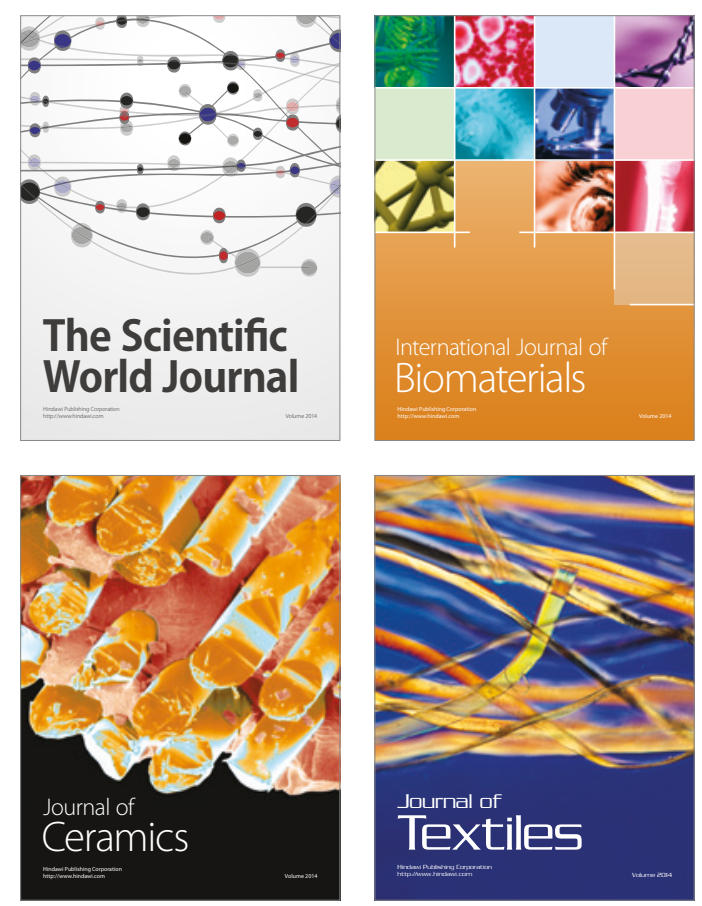